Association for Information Systems

AIS Electronic Library (AISeL)

\title{
Exploring Strategic Orientations in the Age of Digital Transformation: A Longitudinal Analysis of Digital Business Model Patterns
}

\author{
Hannes Kurtz \\ Georg-August-Universität Göttingen \\ Andre Hanelt \\ Universität Kassel \\ Lutz Maria Kolbe \\ Georg-August-Universität Göttingen
}

Follow this and additional works at: https://aisel.aisnet.org/wi2021

Kurtz, Hannes; Hanelt, Andre; and Kolbe, Lutz Maria, "Exploring Strategic Orientations in the Age of Digital Transformation: A Longitudinal Analysis of Digital Business Model Patterns" (2021).

Wirtschaftsinformatik 2021 Proceedings. 2.

https://aisel.aisnet.org/wi2021/HDigitaltransformation17/Track17/2

This material is brought to you by the Wirtschaftsinformatik at AIS Electronic Library (AISeL). It has been accepted for inclusion in Wirtschaftsinformatik 2021 Proceedings by an authorized administrator of AIS Electronic Library (AISeL). For more information, please contact elibrary@aisnet.org. 


\title{
Exploring Strategic Orientations in the Age of Digital Transformation: A Longitudinal Analysis of Digital Business Model Patterns
}

\author{
Hannes Kurtz ${ }^{1}$, Andre Hanelt ${ }^{2}$, Lutz M. Kolbe ${ }^{1}$ \\ ${ }^{1}$ Georg-August-University Göttingen, Information Management, Göttingen, Germany \\ hannes.kurtz01@stud.uni-goettingen.de, lutz.kolbe@wiwi.uni-goettingen.de \\ ${ }^{2}$ University of Kassel, Digital Transformation Management, Kassel, Germany \\ hanelt@uni-kassel.de
}

\begin{abstract}
In the course of digitalization, fundamental mechanisms according to which companies operate are changing. Companies are forced to develop new, digital capabilities, which in turn, alter a company's set of competitive moves and thus its business strategy. While much effort is undertaken to examine digital business strategy through several theoretical lenses, there has never been empirical research on archetypical strategic orientations regarding companies' adoption mechanisms to environmental changes in a digital context. This study fills named research gap by investigating if the established framework of Miles and Snow (1978) is still applicable in the digital age. In doing so, it examines the evolution of digital business models of 40 companies from 2007 until 2017 . We found that all four orientations predominate, but that there are contextual dependencies in their application or change.
\end{abstract}

Keywords: Digital Business Strategy, Strategic Orientations, Digital Business Model, Cluster Analysis.

\section{Introduction}

In the era of proliferating digitalization across societies, digital technologies are fundamentally reshaping traditional business [1]. A reason for this is, that they enable firms to develop and allocate different sets of capabilities and thus alter the company's set of possible competitive moves $[2,3]$. This led to firms in almost every industry conduct a vast amount of initiatives to exploit new digital technologies in order to gain advantage over their competitors $[4,5]$. With this ongoing digital transformation, therefore, conventional wisdom about scale, scope, design, and execution of business strategy is changing. This leads to a new concept named digital business strategy, defined as "organizational strategy formulated and executed by leveraging digital resources to create differential value" [4]. Consequently and given the importance of the topic for contemporary managerial practice, increasingly more researchers set out to advance our understanding of digital business strategy by using different approaches [6].

16th International Conference on Wirtschaftsinformatik,

March 2021, Essen, Germany 
Nevertheless, as Bharadwaj et al. [4] state, many questions remain unanswered and theoretical findings have not been empirically proven yet. For example, in the context of digital transformation, unlike as in classical strategy research, there is a lack of knowledge regarding archetypical strategic orientations concerning organizations' adaption behavior. Here a framework derived by Miles and Snow [7] enables one to classify companies according to their adaption behavior in order to cope with changes in their environment. However, filling this gap is of great importance, as aforementioned digital transformation of nearly every industry creates "both gamechanging opportunities for - and existential threats to - companies" [8]. In order to remain competitive, companies, thus, have to adapt their business models and business strategies, but can come up with different strategic responses to these challenges $[4,6]$.

To examine whether the existing strategic orientations of Miles and Snow [7] still apply in the age of digital transformation may, therefore, aid in advancing our knowledge about digital business strategy and its influence on business practice and digital transformation. Accordingly, we investigate the following research question: Are the predominant types of strategic orientation still valid in a digital context, and do companies change their strategic orientation over time? In order to derive an answer to this question, we analyzed the business models of 40 companies from 2007 until 2017. We thus investigated 240 digital business model pattern configurations using the taxonomy developed by Remane et al. [9]. Employing a two-step cluster analysis, we determine group membership and allocate companies to the four strategic orientations derived by Miles and Snow [7]. This procedure enables us to point out possible changes in the strategic orientation of individual companies. It further allows us to investigate antecedents and reasons for changes in more detail. By analyzing the clusters, we found out that all four strategic orientations prevail in the context of digital business model innovation. Furthermore, we were able to detect changes in the strategic orientations of companies over time.

Our work provides important contributions to information systems (IS) research. To the best of our knowledge, we are the first to set out an empirical examination of strategic orientations from different companies stemming from different industries within a digital context. We, thus, contribute to a better understanding of digital business strategy and digital transformation. Furthermore, we analyzed strategic orientations in the digital age using the construct of digital business model patterns and therefore contributed to a better integration of the concepts business strategy and business models as well as IS and strategic management research.

\section{Background}

\subsection{Digital Business Strategy and Strategic Orientations}

Strategy is often defined as a set of committed choices made by management and a contingent plan of actions and activities designed to achieve a particular goal [10]. These choices relate to topics such as resource investments or the set of a firm's dynamic capabilities needed to deploy these resources [11]. The digital transformation

16th International Conference on Wirtschaftsinformatik, March 2021, Essen, Germany 
of nearly every industry is fundamentally reshaping traditional business practice and, therefore, business strategy. The pervasiveness of digital technology, for instance, leads to a radical change of product architecture, making it difficult to disentangle digital products and services from their underlying IT infrastructure. Besides, increasing digitization of operations and processes within organizations can be seen [12, 13]. As a consequence, scholars such as Drnevich and Croson [11] argue that information technology enhances current non-digital capabilities and enables new digital capabilities. In doing so, it directly affects the mechanisms by which value is created and captured in order to make a profit. It thus alters the business-level strategic alternatives to value creation and capturing. Furthermore, IT-based capabilities determine how much of the value from these opportunities can be captured and help to defend named value against competitors. As a result, information technology matters to business success as well as to business strategy [11]. This leads to a fusion of these two concepts into an overarching phenomenon called digital business strategy [4, 14].

An inherent part of the strategy is the adoption mechanism of a company's strategy formulation process in response to its environment. As a consequence, many scholars view strategy as immutable in the way that over time, companies progress habitual mechanisms to respond to their environmental influences $[15,16]$. Since companies face different environmental influences, they develop different habitual mechanisms resulting in different manifestations of strategy. IS research provides much knowledge about different aspects of digital business strategy. On the other hand, there is no framework for the categorization of strategic orientations with respect to a company's adoption mechanism to environmental changes, as is the case in general management research. In this research domain, a framework developed by Miles and Snow [7] is well established. Because of its attributed longevity, industry-independent nature, and its correspondence with the strategic posture of firms across multiple industries and countries [17], their typology has been the subject of considerable research attention over time [18]. Thereby, the framework condenses, among others, central elements of the resource-based view and dynamic capabilities [19] and postulates four generic types of strategy: First, the Prospectors, present the one extreme of the typology. These companies are first movers, in market/product innovation, creators of change and uncertainty, and flourish in volatile markets $[16,20]$. Furthermore, they can be characterized by risk-taking behavior, loose resource control, and less focus on cost efficiencies [21]. Second, the other extreme, are called Defenders and are characterized as companies offering a stable portfolio of products and exhibiting no or little engagement in market/product innovation [15, 18]. In addition, companies following this strategic orientation are risk-averse [21]. Analyzers, the third type, represent an intermediate type due to balancing a unique combination of characteristics from the two extremes. These companies are often characterized as being second movers and having a selective approach, only imitating prospectors' new products and market opportunities that have successful returns [16]. Lastly, Reactors, are companies that lack a clear strategic orientation resulting from a short-term emphasis [18]. CasadesusMasanell and Ricart [10] point out, that strategy is a set of a company's committed choices and actions. Miles and Snow [7], in turn, state that these choices and activities, over time, result in habitual mechanisms which can be classified into archetypical 
strategy types. Concurrently, it is important to point out that strategy is not the set of activities itself. The set of activities, in contrast, is represented by the business model. The next section briefly characterizes the link between the concepts strategy and business model and shows how business model patterns can be used to evaluate a firm's realized business strategy.

\subsection{Digital Business Model Patterns}

Simply put, a business model describes the general way in which companies create and capture value [22, 23]. Furthermore, the business model in its firm-specific conception allows us to describe and design specific components as well as the interactions between these [23]. With this, the business model consists of different, recurring components. First, the value proposition, which depicts the value as product and service content that is brought to the customer and target segment. Second, the value network, which describes how the value is created and delivered to the customer. Third, the revenue/cost model, which specifies how the value is captured $[24,25]$. The firmspecific conception simultaneously implies that a firm can gain a competitive advantage by making unique choices or linking components differently $[10,26]$. Therefore, the business model concept is a useful lens for understanding a company's underlying logic $[26,27]$. Coming back to the link between business strategy and business model, both concepts intersect, but are not the same. The definition of business strategy above implies that a company has a vision or an idea of how it will position itself or work in the future [28]. The available strategic actions of a company thus are choices that constitute the configuration of the company's business model. More specifically, strategy refers to the contingent plan about which business model a company should use [29]. Hence, the business model concept can be understood as a representation of lower-level instantiations of a company's realized strategy [10, 30].

The majority of business model components are often quite transparent [26]. This is because they usually consist of a recombination of already existing solutions i.e. patterns [31]. Alexander's definition of patterns is that "each pattern describes a problem which occurs over and over again in our environment, and then describes the core of the solution to that problem, in such a way that you can use this solution a million times over, without ever doing it the same way twice" [32]. Business model patterns, thus, are commonly used, and proven configurations of specific components of a business model $[33,34]$. As a consequence, the concept of business model patterns can be used to systematically analyze a company's business model [35]. In their study, Remane et al. [9] classified a database of patterns into purely digital, digitally enabled, and not necessarily digital. They also classified patterns according to their hierarchical impact. Prototypical patterns describe holistic business models of which a company may well use simultaneously such as Apple applying [IT] equipment/component manufacturers as well as Multi-sided platforms. In contrast Solution patterns representing specific building blocks of business models such as Channel maximization. Furthermore, patterns are classified by four meta-components. The value proposition gives an overall view of a company's products and services. Value delivery describes the customer segments, channels for delivering the value proposition and the 
company's customer relationship. Value creation explains the key resources, key activities and key partnerships of a company. Finally, value capture describes the company's revenue streams and cost structure [9].

\section{Methodology, Data Sample \& Analysis}

In order to answer the proposed research question mentioned above, we used a longitudinal data set to assess the evolution of digital business model patterns over time and identify within and across companies and industry sectors [36]. We did this by using a cluster analysis to allocate business model pattern configurations to the four strategic orientations derived by Miles and Snow [7] and are thus in line with earlier IS research [e.g. 37].

The object of the first phase was to create a database containing business model descriptions of companies for the years 2007, 2009, 2011, 2013, 2015, and 2017. Beginning in 2007, it was ensured that the introduction of the iPhone was covered. This can be seen as a breakthrough mobile device leading to more people than ever being connected to the internet. It was necessary to only include companies in the sample for which we could draw on the same source of information to ensure a certain degree of objectivity. We therefore decided to include only publicly traded companies. Accordingly, we used the index "NASDAQ Composite" as a starting point for data collection. The "NASDAQ Composite" lists the largest stocks traded on the NASDAQ (National Association of Securities Dealers Automated Quotation). The index is a price index primarily containing tech-savvy companies. By an API to "Thomson Reuters Datastream," we compiled lists of all index constituents, including their ISIN-Number, SIC-Codes, and stock prices on 31.06. for their respective years. To include smaller companies such as start-ups in the sample, we decided to use the stock price rather than market capitalization as an indicator. Accordingly, we sorted the lists of constituents referring to their price in descending order. For reasons of manageability, the lists were cut to the top 250 companies. It is essential to have company data for the entire period. As a consequence, we reduced the sample to those companies that were in the top 250 for the entire period resulting in a sample of 51 companies to be analyzed. Since a company's business model is the underlying research object, we used Item 1, which is included in the Form $10-\mathrm{K}$ as the description of a company's business model. This document, which is required by the SEC (United States Securities and Exchange Commission), represents annual financial statements in a highly standardized form that companies using the American financial market are obliged to prepare annually. Having Item 1 included in Form 10-K contains a detailed description of each companies' business and thus forms the most accurate, comparable, and comprehensive description possible for this study. According to the rules, not all companies in our sample had to provide the Form 10-K. Therefore, we were only able to download the document for 45 companies for all years. Next, we downloaded the companies' financials for the period from 2007-2017. Not all companies provided data for the whole period resulting in 5 more companies being dropped from the sample. This results in a sample of 40 companies and a database of 240 business model descriptions for the period.

16th International Conference on Wirtschaftsinformatik, 
To investigate business model patterns within the companies' business model descriptions, we used the taxonomy developed by Remane et al. [9]. In order to analyze the business models within the Form 10-K, we generated a matrix for each year. These matrices consist of the individual companies and the business model patterns identified by Remane et al. [9]. In the following, the companies' business descriptions were compared with the descriptions of the individual patterns. For the sake of verifiability, statements matching the patterns have been marked within Item 1 of Form 10-Ks with the corresponding designation. At the same time, the corresponding business model patterns were assigned to the respective company in the matrix. Thereby, companies could apply several prototypical as well as solution patterns simultaneously.

In order to avoid mistakes, encode as accurately as possible, and to grant verifiability, we followed the proven deductive approach of qualitative content analysis developed by Mayring [38]. The following Table 1 shows typical patterns included in the database, their descriptions, and a corresponding reference to these patterns we found in the business description within the Item 1 of Apple's Form 10-K 2013.

Table 1. Exemplary quote within companies' Form 10-K's

\begin{tabular}{|c|c|c|c|}
\hline Pattern Name & $\begin{array}{l}\text { Characteristics } \\
\text { according to } \\
\text { Remané et al. } \\
\text { (2017) }\end{array}$ & $\begin{array}{c}\text { Description of Pattern by } \\
\text { Remané et al. (2017) }\end{array}$ & Company's quote in Form 10-K \\
\hline $\begin{array}{l}\text { (IT) equipment/ } \\
\text { component } \\
\text { manufacturers }\end{array}$ & $\begin{array}{l}\text { Prototypical } \\
\text { Digitally enabled } \\
\text { Value proposition } \\
\text { Value creation }\end{array}$ & $\begin{array}{l}\text { Produce IT equipment and } \\
\text { components }\end{array}$ & $\begin{array}{l}\text { "The Company designs, } \\
\text { manufactures, and markets mobile } \\
\text { communication and media devices, } \\
\text { personal computers, and portable } \\
\text { digital music players." (Form 10-K } \\
2013 \text { - Apple Inc.) }\end{array}$ \\
\hline $\begin{array}{l}\text { Multi-sided } \\
\text { platforms }\end{array}$ & $\begin{array}{l}\text { Prototypical } \\
\text { Purely digital } \\
\text { Value Proposition }\end{array}$ & $\begin{array}{l}\text { Bring together two or more } \\
\text { distinct but interdependent } \\
\text { groups of customers, } \\
\text { where the presence of each } \\
\text { group creates value for the } \\
\text { other groups }\end{array}$ & $\begin{array}{l}\text { "The Company continues to expand } \\
\text { its platform for the discovery and } \\
\text { delivery of third-party digital content } \\
\text { and applications through the iTunes } \\
\text { Store." (Form 10-K } 2013 \text { - Apple } \\
\text { Inc.) }\end{array}$ \\
\hline $\begin{array}{l}\text { Channel } \\
\text { maximization }\end{array}$ & $\begin{array}{l}\text { Prototypical } \\
\text { Digitally enabled } \\
\text { Value delivery } \\
\text { Value capture }\end{array}$ & $\begin{array}{l}\text { Leverage as many channels } \\
\text { as possible to maximize } \\
\text { revenues }\end{array}$ & $\begin{array}{l}\text { "The Company sells its products } \\
\text { worldwide through its online stores, } \\
\text { its retail stores, its direct sales force, } \\
\text { and third-party wholesalers, resellers, } \\
\text { and value-added resellers." (Form } \\
\text { 10-K } 2013 \text { - Apple Inc.) }\end{array}$ \\
\hline
\end{tabular}

The target of the third phase was the empirical determination of group membership by conducting a cluster analysis. In doing so, we performed a two-step cluster analysis in SPSS. By using the Log-likelihood distance, this approach can cluster continuous as well as categorical variables [39]. We divided our period of investigation into three separate periods to control for possible time lacks in strategic decisions to investigate the evolution of constituents and characteristics for the specific clusters. Thereby each cluster represents a strategic orientation of the Miles and Snow's [7] typology. We used three variables to characterize the derived clusters which the following Table 2 shows. 
Table 2. Expected value of variables for each strategic orientation

\begin{tabular}{cccccc}
\hline Variable & Controls for & Defender & Reactor & Analyzer & Prospector \\
\hline $\begin{array}{c}\varnothing \text { Number of } \\
\text { patterns }\end{array}$ & $\begin{array}{c}\text { Diversity of } \\
\text { configurations }\end{array}$ & Low & No & Medium & High \\
$\begin{array}{c}\varnothing \text { Change of } \\
\text { pattern }\end{array}$ & $\begin{array}{c}\text { Changes within } \\
\text { configurations }\end{array}$ & No/Low & No & $\begin{array}{c}\text { Low / } \\
\text { Moderate }\end{array}$ & $\begin{array}{c}\text { Moderate / } \\
\text { High }\end{array}$ \\
$\begin{array}{c}\text { Variance of } \\
\text { pattern change }\end{array}$ & $\begin{array}{c}\text { Continuity of } \\
\text { change within } \\
\text { configurations }\end{array}$ & No/Low & No & Low & $\begin{array}{c}\text { Moderate / } \\
\text { High }\end{array}$ \\
\hline
\end{tabular}

In the last phase, we qualitatively analyzed each cluster by using the taxonomy derived by Remane et al. [9], the matrices per year, and the statistics from the cluster analysis. First, we examined the clusters by the number of companies within the cluster, the industrial affiliation of these companies, and the focus of their business. In the next step, we analyzed the configurations within the clusters and their evolution over the period using the predefined variables prototypical vs. solution-oriented, fully digital vs. digitally-enabled, value proposition, value delivery, value creation, and value capture originating from the meta-components and dimensions of the taxonomy.

\section{$4 \quad$ Findings}

\subsection{Strategic Orientations in the Digital Age}

Table 3 illustrates the results of the two-way clustering. It shows a distance silhouette coefficient of 0.8 for the first period and 0.7 for the second and third period. Besides, the ratio of cluster shrinks from 16 to 2.67 over the course of time. Reasons for this is that the cluster representing Analyzers levels down over time, while the cluster representing Prospectors increases by two in the second, and by three companies in the third period. The clusters representing Defenders and Reactors, in contrast, are stable over time.

Table 3. Overview of clustering

\begin{tabular}{cccc}
\hline Period & $\begin{array}{c}\text { Distance of Silhouettes } \\
\text { Coefficient }\end{array}$ & $\begin{array}{c}\text { Number of Companies within the } \\
\text { Cluster }\end{array}$ & Ratio cluster \\
\hline T1 (2007 \& 2009) & 0.8 & $\begin{array}{c}\text { Defender (7)*, Reactor (16), } \\
\text { Analyzer (16), Prospector (1) }\end{array}$ & 16 \\
T2 (2011 \& 2013) & 0.7 & $\begin{array}{c}\text { Defender (7), Reactor (16), } \\
\text { Analyzer (14), Prospector (3) }\end{array}$ & 5.33 \\
T3 (2015 \& 2017) & 0.7 & $\begin{array}{c}\text { Defender (7), Reactor (16), } \\
\text { Analyzer (11), Prospector (6) }\end{array}$ & 2.67 \\
\hline
\end{tabular}

*Number of companies included in a cluster within brackets 
Table 4 lists the companies and their industry affiliation included in the clusters within the individual periods. Especially companies stemming from a rather asset-heavy industry such as (20) Food and Kindred Products, (53) General Merchandise Store or (13) Oil and Gas Extraction or Mining can be assigned to the cluster Defender. The strategic orientation Reactor, in turn, merely represents companies from the B2B sector such as (28) Chemicals and Allied Products, (35) Industrial and Commercial Machinery and Computer Equipment. Companies of both clusters do not change their strategic orientation within our period of investigation. In contrast, the cluster representing the strategic orientation of Analyzers includes companies from a variety of industries. Within this cluster, the companies Amazon and Apple changed their strategic orientations from the first to the second period. From then on they can be considered as Prospectors. Both companies already had a strong digital background and can be described as tech-savvy. From the second to the third period, the companies Booking Holdings, Costar and Morningstar also changed their strategic orientations from being Analyzers to being Prospectors. Interesting to note is, that in contrast to the first two companies mentioned, these companies exhibit asset-light business models. The last cluster, representing Prospectors, at the beginning only contained Alphabet, stemming from the industry (73) Business Services. Over the course of time it increases by integrating aforementioned five companies.

Table 4. Overview of Companies within clusters for each period

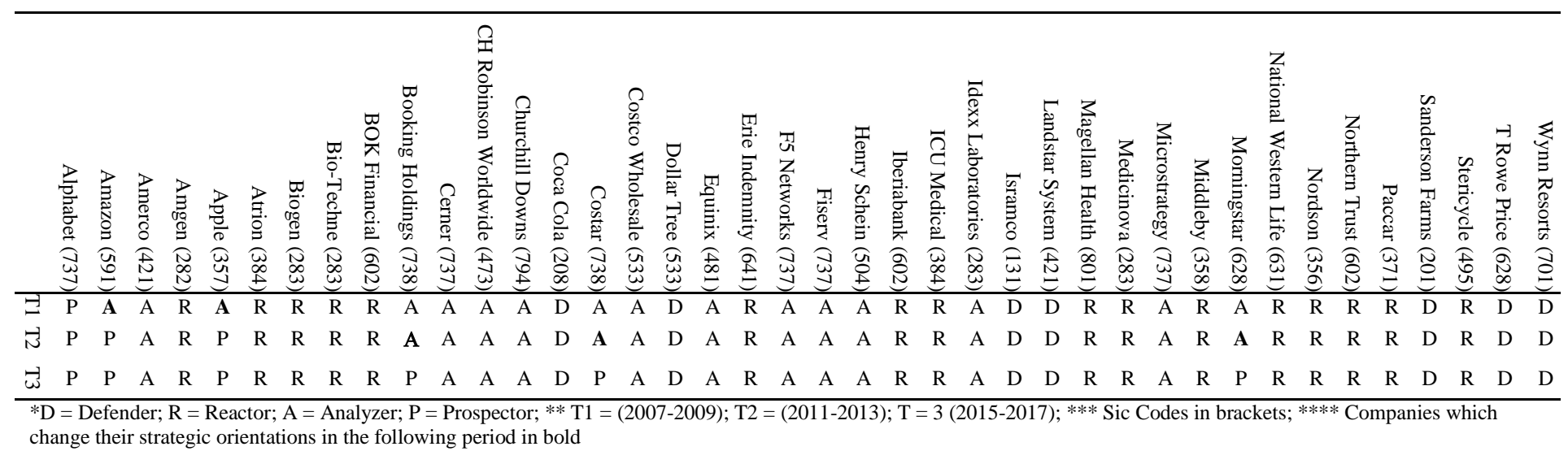

16th International Conference on Wirtschaftsinformatik, March 2021, Essen, Germany 
With respect to the characteristics of the individual DBMP configurations of the respective strategic orientations, significant differences can be identified, which are typical for the respective strategic orientations. The strategic orientation Defender exhibits the smallest number of digital business model pattern. With 3.39 digital business model pattern, the cluster representing Analyzers shows the average value. In contrast, Prospectors have by far the highest number of digital business model patterns. Simultaneously, Prospectors are the only companies that exhibit changes within their configurations in the first period. Taking a look at the evolution of configuration characteristics, in contrast to Analyzers and Prospectors, the configuration characteristics of Defenders do not change over time. The first two strategic orientations, however, both exhibit a higher amount of digital business model patterns in the second period, which decreases again in the third. The same trend can be seen with the exchange of patterns. Regarding the hierarchical impact, Defenders clearly show a solution-oriented configuration. With an amount of 90 percent, they further apply a mostly digital business model pattern. The configurations of Analyzers and Prospectors share to a large extend the same characteristics and exhibit more prototypical-oriented and thus holistic digital business model pattern configurations. At the same time, they have less purely digital configurations and thus exhibit much digital business model pattern which are digitally enabled. Consequently, they have a strong physical component in their digital business model pattern configuration. Furthermore, the orientation of the configurations of both strategic orientations is only slightly changing throughout the investigation. However, it can be stated that the orientation towards prototypical as well as towards digitally enriched business model pattern is increasing from period one to period three. Concerning the dimensions the individual strategic orientations target, it is striking that the strategic orientation Defender has a focus on the dimension value proposition and value capture. Concurrently, with only $10 \%$, it neglects the dimension value creation. This fits exceptionally well with the very solution-oriented approach of Defenders. It further leads to the picture that companies following this strategic orientation enrich their already existing, physical business with fully digital and solution-oriented business model patterns such as Channel maximization or Online advertising and public relations. The value creation continues to take place primarily in the traditional business. Coming to Analyzers and Prospectors, we find different configurations. The configurations of both strategic orientations are comparatively balanced but differentiate from each other in nuances. Thus, with 82 percent of the applied patterns, prospectors have a much stronger focus on the business model dimensions value creation, whereas this focus is lower regarding the strategic orientation of Analyzers. At the same time, it is noticeable that the weighting of the patterns of Prospectors changes more strongly from the second to the third period than it does regarding the configuration of Analyzers. This may be due to a stronger exchange of patterns or the change in the strategic orientation of three companies from an approach of an Analyzer to one of a Prospector. The following Table 5 shows the characteristics of digital business model configurations of all strategic orientations for all periods in more detail. 
Table 5. Overview of cluster characteristics over all periods

\begin{tabular}{|c|c|c|c|c|c|c|c|c|c|c|c|c|c|c|c|c|c|}
\hline $\begin{array}{l}\text { Strategic } \\
\text { Orientation }\end{array}$ & 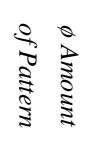 & 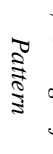 & 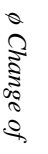 & 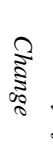 & 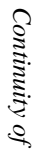 & 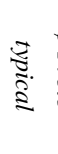 & $\begin{array}{l}0 \\
7 \\
0 \\
0 \\
1\end{array}$ & 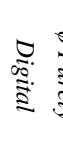 & $\begin{array}{l}0 \\
2 \\
\vdots \\
\frac{2}{2}\end{array}$ & 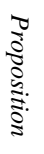 & 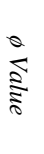 & $\frac{\sqrt{3}}{\sqrt[3]{3}}$ & 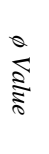 & $\begin{array}{l}\overrightarrow{0} \\
\stackrel{5}{0} \\
\mathbf{0}\end{array}$ & 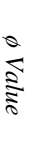 & ह & $\frac{\substack{\infty \\
\frac{1}{2}}}{2}$ \\
\hline
\end{tabular}

\begin{tabular}{|c|c|c|c|c|c|c|c|c|c|}
\hline T1 & & & & & & & & & \\
\hline Defender & 2.29 & 0.00 & 0.00 & $10 \% *$ & $90 \%$ & $69 \%$ & $31 \%$ & $10 \%$ & $62 \%$ \\
\hline Reactor & 0.00 & 0.00 & 0.00 & - & - & - & - & - & - \\
\hline Analyzer & 3.93 & 0.00 & 0.89 & $64 \%$ & $36 \%$ & $50 \%$ & $50 \%$ & $62 \%$ & $42 \%$ \\
\hline Prospector & 15.0 & 4.00 & 5.20 & $64 \%$ & $36 \%$ & $68 \%$ & $32 \%$ & $79 \%$ & $47 \%$ \\
\hline \multicolumn{10}{|l|}{$T 2$} \\
\hline Defender & 2.29 & 0.00 & 0.00 & $10 \%$ & $90 \%$ & $69 \%$ & $31 \%$ & $10 \%$ & $62 \%$ \\
\hline Reactor & 0.00 & 0.00 & 0.00 & - & - & - & - & - & - \\
\hline Analyzer & 4.61 & 0.71 & 0.74 & $69 \%$ & $31 \%$ & $56 \%$ & $44 \%$ & $69 \%$ & $39 \%$ \\
\hline Prospector & 16.8 & 2.67 & 3.03 & $63 \%$ & $37 \%$ & $55 \%$ & $45 \%$ & $82 \%$ & $41 \%$ \\
\hline \multicolumn{10}{|l|}{$T 3$} \\
\hline Defender & 2.29 & 0.00 & 0.00 & $10 \%$ & $90 \%$ & $69 \%$ & $31 \%$ & $10 \%$ & $62 \%$ \\
\hline Reactor & 0.00 & 0.00 & 0.00 & - & - & - & - & - & - \\
\hline Analyzer & 4.09 & 0.27 & 0.51 & $67 \%$ & $33 \%$ & $49 \%$ & $51 \%$ & $69 \%$ & $34 \%$ \\
\hline Prospector & 10.7 & 2.75 & 2.30 & $68 \%$ & $32 \%$ & $69 \%$ & $31 \%$ & $76 \%$ & $51 \%$ \\
\hline
\end{tabular}

\subsection{Evolution of Digital Business Model Configurations and Changes in Strategic Orientations}

The number of companies in clusters is not consistent throughout the period of investigation. Hence, it is evident that several companies had changed group membership throughout the investigation, suggesting fundamental changes in their strategic orientation. The following Tables 6, 7, and 8 show exemplary evolutions of digital business model pattern configurations of three companies. Firstly, Apple as an example of a company changing its strategic orientation from being an Analyzer to being a Prospector. Secondly, F5 Networks as a company following the strategic orientation of an Analyzer over the whole period. Lastly, Coca Cola which clearly can be assigned to the strategic orientation of a Defender.

Apple's core configuration consists of prototypical business model patterns such as Marketplace exchange, or Multi-sided platforms. These patterns, as well as few others, build a stable core over the course of time. Other prototypical, as well as solutionoriented patterns, are placed and exchanged around these core patterns. Thereby they either take on a supporting function or act as own independent businesses. For example, patterns such as E-shop or Bricks + clicks appear in the wake of time and disappear again if necessary. Both patterns, as well as patterns such as Channel maximization, clearly pursue the objective to sell the products produced by Apple and to open up various distribution channels. Other patterns, such as Trust intermediary, in turn, 
represent independent businesses with their revenue streams. An important role in Apple's configuration and its evolution is played by the digitally enabled patterns (IT) equipment/component manufacturer and Digitally charged products. In the second period, the company makes the most changes and builds up many patterns. Taking a closer look, one can see that most of the patterns adapted in this period, such as Digital add-on, Product as point of sales, or Remote usage and condition monitoring, closely related to Apple's hardware products.

Table 6. Evolution of Apple's digital business model pattern configuration

\begin{tabular}{cl}
\hline Year & \multicolumn{1}{c}{ Applied Patterns } \\
\hline 2007 & $\begin{array}{l}\text { (IT) equipment/component manufacturers*, Channel maximization, Digitally charged } \\
\text { products, Digitization, IP trader, Marketplace exchange, Multi-sided platforms, Software } \\
\text { firms, }\end{array}$ \\
2009 & $\begin{array}{l}\text { (IT) equipment/component manufacturers, Channel maximization, Digitally charged products, } \\
\text { Digitization, E-Shop, IP trader, Marketplace exchange, Multi-sided platforms, Software firms, }\end{array}$ \\
2011 & $\begin{array}{l}\text { (IT) equipment/component manufacturers, Channel maximization, Digital add-on, Digital lock- } \\
\text { in, Digitally charged products, Digitization, E-Shop, Infrastructure services firms, IP trader, }\end{array}$ \\
& Marketplace exchange, Multi-sided platforms, Software firms, \\
2013 & $\begin{array}{l}\text { (IT) equipment/component manufacturers, Bricks + clicks, Business intelligence, Channel } \\
\text { maximization, Digital add-on, Digital lock-in, Digitally charged products, Digitization, E-Shop, } \\
\text { Inventor, Licensing, Marketplace exchange, Multi-sided platforms, Physical freemium, Product } \\
\text { as point of sales, Remote usage and condition monitoring, Selling online services, Software firms, } \\
\text { Trust intermediary, } \\
\text { (IT) equipment/component manufacturers, Channel maximization, Digitally charged products, } \\
\text { Digitization, E-Shop, Infrastructure services firms, Marketplace exchange, Multi-sided } \\
\text { platforms, Software firms, Trust intermediary, }\end{array}$ \\
(IT) equipment/component manufacturers, Channel maximization, Digitally charged products, \\
Digitization, E-Shop, Marketplace exchange, Multi-sided platforms, Selling online services, \\
Software firms, Trust intermediary,
\end{tabular}

Taking a look at the digital business model pattern configuration of another Analyzer, F5 Networks, the two prototypical patterns Infrastructure service firm and Software firm build the core of the configuration. Interesting to note is that the pattern Customer supplier of hardware was exchanged for the pattern (IT) equipment/component manufacturer in the second period. Furthermore, the company adds the pattern Application service providers in the third period. This pattern promises ongoing revenue through continues service fees and hence represents a modification of the traditional software business F5 Networks already was in. Accordingly, the company has primarily adapted patterns that represent a further development or superior solution to the previous core business. This showcases the behavior of an Analyzer who assess possibilities and is more wait-and-see in its actions. 
Table 7. Evolution of F5 Networks' digital business model pattern configuration

\begin{tabular}{ll}
\hline Year & \multicolumn{1}{c}{ Applied Patterns } \\
\hline 2007 & Custom suppliers of hardware, Infrastructure services firms*, Software firms, \\
2009 & Custom suppliers of hardware, Infrastructure services firms, Software firms, \\
2011 & Custom suppliers of hardware, Infrastructure services firms, Software firms, \\
2013 & (IT) equipment/component manufacturers, Infrastructure services firms, Software firms, \\
2015 & $\begin{array}{l}\text { (IT) equipment/component manufacturers, Application service providers, Infrastructure services } \\
\text { firms, Software firms, }\end{array}$ \\
2017 & $\begin{array}{l}\text { (IT) equipment/component manufacturers, Application service providers, Infrastructure services } \\
\text { firms, Software firms, }\end{array}$ \\
\hline
\end{tabular}

* Digital business model patterns in bold represent the core configuration.

In contrast, the company Coca Cola represents the approach of a Defender. Its business can be described as asset-heavy and physical. Nevertheless, the company exhibits the digital business model patterns Channel maximization, and Online advertising, and public relations. These solution-oriented and fully digital business model patterns are clearly pursuing the goal of strengthening the core business and increasing sales of produced beverages. At the same time, the evolution of business model patterns does not change over time, suggesting that the company sees digital technology as an enabler rather than a direct source of value creation and delivery. There is also evidence for this shown by the lack of mention of business model patterns such as Enterprise resource planning, which usually is the standard in such a business model.

Table 8. Evolution of Coca Cola's digital business model pattern configuration

\begin{tabular}{ll}
\hline Year & \multicolumn{1}{c}{ Applied Patterns } \\
\hline 2007 & Channel maximization, Online advertising and public relations, \\
2009 & Channel maximization, Online advertising and public relations, \\
2011 & Channel maximization, Online advertising and public relations, \\
2013 & Channel maximization, Online advertising and public relations, \\
2015 & Channel maximization, Online advertising and public relations, \\
2017 & Channel maximization, Online advertising and public relations, \\
\hline
\end{tabular}

* Digital business model patterns in bold represent the core configuration. 


\section{$5 \quad$ Discussion and Conclusion}

\subsection{Discussion of Findings}

Our findings reveal important new perspectives. All strategic orientations derived by Miles and Snow [7] are present within our sample. At the same time, we can see contextual dependencies with regard to the application of specific strategic orientations and changes to new ones. These refer to the industry a company is in and to the materiality of its core product or service.

Companies applying the strategic orientation of a Reactor either do not have a clear digital business strategy or fail to communicate it. Both may indicate that they consider the formulation and execution of a digital business strategy to be less promising. At the same time, these companies mainly stem from B2B industries with strong engineering foci as well as high tech and knowledge-intensive products in niche markets. Reasons may be, that the industry characteristics simply do not call for a digital business strategy or the technology is not yet mature enough to provide a significant benefit. At the same time, our study raises two further explanations. Our study shows that certain business model patterns are communicated less strongly than patterns that appeal to a company's value proposition. Prominent example are patterns such as Enterprise resource planning or Supply chain management which are not communicated even if they are central to specific companies' business models. While Coca Cola, for instance, is traditionally viewed as a brand-driven company, there is no doubt about the influence of Coca Cola's supply chain on the company's success [40]. Companies such as Coca Cola can perceive these patterns as commodities and, hence, communicate them less strongly than other patterns leading to our second explanation. Defenders often stem from asset-heavy industries but, as opposed to Reactors, have a stronger customer interface. Accordingly, these companies communicate their digital business model pattern much stronger. Concurrently, these patterns are often solution-oriented, digital patterns which are easy to implement. Furthermore, these patterns create direct value to the customers or support the actual value proposition of a physical product, such as the pattern Channel maximization does. This may be an indication that many companies and entire industries still do not understand the importance of digital technologies for creating differential value and competitive advantages in nuances. Accordingly, they underestimate the effect of digital technology on the actual success of a company. Therefore, they may tend to consider IT strategy to be subordinate to business strategy and still do not assign them any strategic relevance at the business level.

With regard to the context of product materiality, our study shows that purely digital business models, such as those of software firms, do not necessarily result in more strategic flexibility and increased option space of competitive moves. Hence, our findings are in contrast to statements from other studies that say that characteristics of digital technology per se lead to more freedom and flexibility [41]. Many software firms within our sample follow the strategic orientation of an Analyzer and show a certain homogeneity of the applied and exchanged patterns. In addition, their configurations exhibit a strong specialization. All of these company's adopted the prototypical pattern Application service provider at the same time. The pattern is very similar to the pattern

16th International Conference on Wirtschaftsinformatik, March 2021, Essen, Germany 
named Software firm and only refines the way value is created. Apart from these "punctual" improvements, most pure software companies did not undertake any farreaching innovations. Rather, the companies which combined different technologies (e.g. physical and digital) showed the most volatile business model configuration and were engaged in different initiatives, even at the same time. This leads to platforms which often base on physical devices. Apple for instance, digitally enriched their hardware products and, thus, was able to establish a digital platform. This increased Apple's option space and enabled the company to experiment with different patterns and enter new businesses. Here we can see links to the work of Nambisan et al. [42, 43], which describe a general shift from in-house innovation to innovation networks in business ecosystems based on digital platforms. This reinforces the statement made by Yoo et al. [44] that says that one of the key imperatives of innovation is the question of how to design, build and sustain a vibrant platform that enables different actors to settle their products on it.

\subsection{Implications for IS research and business practice}

Our study unravels important insights by shedding light on the nature of strategic orientations in a digital context. Many studies have examined the concept of digital business strategy through several theoretical lenses. To the best of our knowledge, we are the first to empirically examine established generic types of strategic behavior, derived by Miles and Snow [7], in the context of an ongoing digital transformation. First of all, we were able to show that the framework of Miles and Snow [7] is still applicable in the digital age. Nevertheless, while all strategic orientations prevail, we were able to show contextual differences with regard to the application of the individual strategy types. These are reflected in the dimensions of industrial environment and materiality of the product or service. Thus, in contrast to other studies, we can show that the digital transformation in individual industries seems to be proceeding differently, or that digital strategies in the industries have a different status. Furthermore, we were able to show that digital business model configurations do not per se lead to increased freedom.

Furthermore, we show that (digital) business model patterns are a useful tool to analyze a company's (digital) business model and draw conclusions about its (digital) business strategy. Practitioners can use this tool to counteract uncertainties in the analysis, formulation and implementation of digital business strategies, since digitization is often the subject of strong hype cycles and the use of digital technologies and digital business models is often very unreflective. A wait-and-see attitude and the adaptation of business models at the right time, as Apple shows in our example, is often much more promising than simply trying out all business models at once. At the same time, however, it must be pointed out that digital technologies influence firm performance and underestimating them can be problematic for companies. A strategic consideration of digital issues on the business level is therefore indispensable. 


\subsection{Limitations and future research}

Our study has three limitations. First, the creation of our database. Here we only included publicly traded companies. Thus, it remains to be questioned whether the inclusion of non-publicly traded companies would change our results and how feasible our findings are, for instance, with regard to different company sizes. Furthermore, due to using the NASDAQ Composite, we limited our study to companies based and traded in the United States of America. Furthermore, the index is known for listing highly tech-savvy companies. Using this index was necessary in order ensure a consistent and stable foundation as well as the availability of the Form 10-K. At the same time, taking a broader sample from companies all over the world would have enriched our study, as it would have included several perspectives and different approaches of companies from other cultural and environmental contexts. Second, survivorship bias can significantly influence the results of a study. Since we only observed companies within the top 250 of the NASDAQ Composite according to their closing price it is possible to draw wrong conclusions. The index is perceived as very volatile and it can be misleading to exclude companies and their adaption behavior, which had a different closing price at that specific time. However, switching to the NASDAQ-100 would not have been beneficial as we also wanted to give smaller companies known to experiment with new business models, such as start-ups, the opportunity to get into sample. Third, the accuracy of the Form 10-Ks can be questioned. Other scholars such as Weill et al. [45] also have used this document as a source for analyzing a company's business model. The document consequently can be perceived as a reliable source. In addition, companies are subject to strict regulations when filling it. Concurrently, they are free to decide which part of their business models they want to describe. Therefore, it cannot be completely guaranteed that all business model patterns are contained in the Form $10-\mathrm{K}$ and whether all nuances of digital business strategy were thus examined. This makes further research necessary to counter these limitations. It is also important to empirically evaluate the four strategic orientations in a digital context and gain more insights concerning moderating variables such as industry characteristics or management decisions. At the same time, a qualitative approach could be useful to obtain in-depth information about companies and applied digital business strategies and their nuances. Furthermore, the strategic orientations also have to be linked more closely to already existing theoretical concepts such as path dependency, design capital, or digital posture. In addition, future research with a qualitative approach can help to solve aforementioned problems and limitations by using interviews or case studies, for example.

\section{$6 \quad$ References}

1. Tilson, D., Lyytinen, K., Sørensen, C.: Digital Infrastructures: The Missing IS Research Agenda. Inf. Syst. Res. 21, 748-759 (2010).

2. Mithas, S., Tafti, A., Mitchell, W.: How a Firm's Competitive Environment and Digital Strategic Posture Influence Digital Business Strategy. MIS Q. 37, 511-536 (2013).

3. Pavlou, P.A., El Sawy, O.A.: From IT Leveraging Competence to Competitive

16th International Conference on Wirtschaftsinformatik,

March 2021, Essen, Germany 
Advantage in Turbulent Environments: The Case of New Product Development. Inf. Syst. Res. 17, 198-227 (2006).

4. Bharadwaj, A., El Sawy, O.A., Pavlou, P.A., Venkatraman, N.: Digital Business Strategy: Toward a Next Generation of Insights. MIS Q. 37, 471-482 (2013).

5. Matt, C., Hess, T., Benlian, A.: Digital Transformation Strategies. Bus. Inf. Syst. Eng. 57, 339-343 (2015).

6. Vial, G.: Understanding digital transformation: A review and a research agenda. J. Strateg. Inf. Syst. 28, 118-144 (2019).

7. Miles, R., Snow, C.: Organizational Strategy, Structure, and Process. Acad. Manag. Rev. 3, 546-562 (1978)

8. Sebastian, I.M., Ross, J.W., Beath, C., Mocker, M., Moloney, K.G., Fonstad, N.O.: How Big Old Companies Navigate Digital Transformation. MIS Q. Exec. 16, 197-213 (2017).

9. $\quad$ Remane, G., Hanelt, A., Tesch, J.F., Kolbe, L.M.: The Business Model Pattern Database — a Tool for Systematic Business Model Innovation. Int. J. Innov. Manag. 21, 1-61 (2017).

10. Casadesus-Masanell, R., Ricart, J.E.: From Strategy to Business Models and onto Tactics. Long Range Plann. 43, 195-215 (2010).

11. Drnevich, P.L., Croson, D.C.: Information Technology and Business -Level Strategy: Toward an Integrated Theoretical Perspective. MIS Q. 37, 483-509 (2013).

12. El Sawy, O.A.: The IS Core IX: The 3 Faces of Information System Identity: Connection, Immersion, and Fusion. Commun. Assoc. Inf. Syst. 12, 588-598 (2003).

13. Yoo, Y., Henfridsson, O., Lyytinen, K.: The New Organizing Logic of Digital Innovation: An Agenda for Information Systems Research. Inf. Syst. Res. 21, 724-735 (2010).

14. Coltman, T., Tallon, P.P., Sharma, R., Queiroz, M.: Strategic IT alignment: twenty-five years on. J. Inf. Technol. 30, 91-100 (2015).

15. Hambrick, D.C.: Some tests of the effectiveness and functional attributes of Miles and Snow's strategic types. Acad. Manag. J. 26, 5-26 (1983).

16. Haj Youssef, M.S., Christodoulou, I.: Assessing Miles and Snow Typology through the Lens of Managerial Discretion: How National-Level Discretion Impact Firms Strategic Orientation. Manag. Organ. Stud. 4, 67-73 (2017).

17. Hambrick, D.C.: On the staying power of defenders, analyzers, and prospectors. Acad. Manag. Exec. 17, 115-118 (2003).

18. Desarbo, W.S., Di Benedetto, C.A., Song, M., Sinha, I.: Revisiting the miles and snow strategic framework: Uncovering interrelationships between strategic types, capabilities, environmental uncertainty, and firm performance. Strateg. Manag. J. 26, 47-74 (2005).

19. Shortell, S.M., Zajac, E.J.: Perceptual and Archival Measures of Miles and Snow' s Strategic Types: A Comprehensive Assessment of Reliability and Validity. Acad. Manag. J. 33, 817-833 (1990).

20. Walker, O., Boyd, H., Mullin, J.: Marketing Strategy: Planning and Implementation. Irwin/MCGraw-Hill, Homewood (2003).

21. Segars, A.H., Grover, V., Kettinger, W.J.: Strategic users of information technology: a longitudinal analysis of organizational strategy and performanc. J. Strateg. Inf. Syst. 3, 261-288 (1994).

22. Chesbrough, H.: Business model innovation: It's not just about technology anymore. Strateg. Leadersh. 35, 12-17 (2007).

23. Demil, B., Lecocq, X.: Business Model Evolution: In Search of Dynamic Consistency. Long Range Plann. 43, 227-246 (2010).

24. Bohnsack, R., Pinkse, J., Kolk, A.: Business models for sustainable technologies: Exploring business model evolution in the case of electric vehicles. Res. Policy. 43, 
284-300 (2014).

25. Morris, M., Schindehutte, M., Allen, J.: The entrepreneur's business model: toward a unified perspective. J. Bus. Res. 58, 726-735 (2005).

26. Teece, D.J.: Business Models, Business Strategy and Innovation. Long Range Plann. 43, 172-194 (2010).

27. Osterwalder, A., Pigneur, Y., Tucci, C.L.: Clarifying Business Models: Origins, Present, and Future of the Concept. Commun. Assoc. Inf. Syst. 16, 1-25 (2005).

28. Wirtz, B.W., Pistoia, A., Ullrich, S., Göttel, V.: Business Models: Origin, Development and Future Research Perspectives. Long Range Plann. 49, 36-54 (2016).

29. Casadesus-Masanell, R., Ricart, J.E.: How to Design A Winning. Harv. Bus. Rev. 89, 3-9 (2011).

30. Al-Debei, M.M., Avison, D.: Developing a unified framework of the business model concept. Eur. J. Inf. Syst. 19, 359-376 (2010).

31. Gassmann, O., Frankenberger, K., Cisk, M.: The Business Model Navigator: 55 Models that will Revolutionise your Business. UK: Pearson, Harlow (2014).

32. Alexander, C., Ishikawa, S., Silverstein, M.: A Pattern Language: Towns, Buildings, Constructions. Oxford University Press, New York, USA (1977).

33. Lüttgens, D., Diener, K.: Business Model Patterns Used as a Tool for Creating (new) Innovative Business Models. J. Bus. Model. 4, 19-36 (2016).

34. Rudtsch, V., Gausemeier, J., Gesing, J., Mittag, T., Peter, S.: Pattern-based Business Model Development for Cyber-Physical Production Systems. Procedia CIRP. 25, 313319 (2014).

35. Abdelkafi, N., Makhotin, S., Posselt, T.: Business model innovations for electric mobility: What can be learned from existing business model patterns? Int. J. Innov. Manag. 17, 1-41 (2013).

36. Yin, R.K.: Discovering the future of the case study. method in evaluation research. Eval. Pract. 15, 283-290 (1994).

37. Haas, P., Blohm, I., Leimeister, J.M.: An Empirical Taxanomy of Crowdfunding Intermediaries. Thirty Fifth Int. Conf. Inf. Syst. 1-18 (2014).

38. Mayring, P.: Qualitative content analysis: theoretical foundation, basic procedures and software solution. (2014).

39. Řezanková, H.: Cluster analysis and categorical data. Statistika. 46, 216-232 (2009).

40. Evans, R., Danks, A.: Strategic supply chain management: Creating shareholder value by aligning supply chain strategy with business strategy. In: Gattorna, J. and Jones, T. (eds.) Strategic Supply Chain Alignment: Best Practice in Supply Chain Management. pp. 32-52. , Routledge (1998).

41. Huang, J., Henfridsson, O., Liu, M.J., Newell, S.: Growing on Steroids: Rapidly Scaling the User Base of Digital Ventures Through Digital Innovation. MIS Q. 41, 301-314 (2017).

42. Nambisan, S.: Architecture vs. ecosystem perspectives: Reflections on digital innovation. Inf. Organ. 28, 104-106 (2018).

43. Nambisan, S., Lyytinen, K., Majchrzak, A., Song, M.: Digital Innovation Management: Reinventing Innovation Management Research in a Digital World. MIS Q. 41, 239-253 (2017).

44. Yoo, Y., Boland, R.J., Lyytinen, K., Majchrzak, A.: Organizing for Innovation in the Digitized World. Organ. Sci. 23, 1398-1408 (2012).

45. Weill, P., Vitale, M.: Place to Space: Migrating to E-Business Models., Boston, USA (2001). 